$$
\begin{aligned}
& S \text { sciendo International Conference KNOWLEDGE-BASED ORGANIZATION } \\
& \begin{array}{lll}
\text { Vol. XXV No } 2 & 2019
\end{array}
\end{aligned}
$$

\title{
SECULAR TRENDS IN BMI AND WAIST CIRCUMFERENCE AND THE PREVALENCE OF OVERWEIGHT AND OBESITY IN AUSTRIAN CANDIDATES FOR CONSCRIPTION FROM 2007 TO 2016
}

\author{
Horst STOCKER \\ “Theresian" Military Academy, Wiener Neustadt, Austria \\ horst.stocker@bmlv.gv.at
}

\begin{abstract}
The increase of prevalence of overweight and obesity progressed worldwide and is associated with lifetime diseases. Operational readiness of armed forces is depending on anthropometric data and physical fitness of soldiers. The aim of the study was the investigation of temporal and regional trends of BMI and waist circumference of Austrian conscripts.Data came from the Ministry of Defence of Austria. Mean of body mass (BM, $\mathrm{kg}$ ), body mass index (BMI, $\mathrm{kg} / \mathrm{m}^{2}$,) and waist circumference $(W C, \mathrm{~cm})$ across age, urbanity and regions were analysed, effect size was checked by Cohen's $d$ and $f$ eta. Significance was selected at $p$ values $<0.05$.Mean of BM, BMI and $W C$ showed significant differences, effect sizes were trivial. A significant high correlation was ascertained by BM $(r=0.78-0.82)$ and BMI $(r=0.77-0.81)$ to $W C$ in all age cohorts. Regional differences were detected in $B M, B M I$ and $W C$. The results show a significant increase of $B M, B M I$ and WC in the years 2007 to 2010 and a stabilisation during the rest of investigation period. Prevalence of overweight and obesity in young men has reached a worrying level for public health in Austrian society.
\end{abstract}

Keywords: BMI, Waist circumference, prevalence of overweight of conscripts

\section{Introduction}

Medical and epidemiological studies show, that also in Europe overweight and obesity strongly increased $[1,2,3]$. Particularly in industrialized countries, this phenomenon has reached epidemic rates [4]. Obesity is associated with co-morbidities as high blood pressure, chronic metabolic syndrome, diabetes type 2 or cardiovascular diseases although in young adults $[5,6]$.

The categorisation for overweight and obesity for adults by the World Health Organization (WHO) with body mass index (BMI) is valid consistently since $1995[7,8]$.

Most information about overweight and obesity in the official WHO data bank are based on BMI data.
In contrast to more susceptible methods like waist circumference, waist-to-hip-ratio or measurement of skin fold thickness BMI is basically an indirect measurement. However no statements about body fat distribution can be made $[2,9,10]$.

Military activities are dominated by high physical and psychological load. The assessment for armed forces is based on health and physical fitness. Several studies have demonstrated that poor muscle fitness and endurance as well as high or very low BMI are risk factors for overuse injuries and sickness absence from military basic training. So from the economical point of view the selection process is important for classification for specific military tasks. 
Investigations of samples of Austrian population showed that prevalence of overweight rose significantly from $13.3 \%$ to $15.7 \%$, and obesity from $2.6 \%$ to $5.4 \%$ $(p<0.001)$ over a period of 20 years [3]. Consequently, the mean of BMI and mean WC registered a significant increase. Furthermore, with regard to the prevalence of overweight and obesity, as well as the mean BMI and $\mathrm{WC}$, a significant east west gradient was detected. Besides, urban citizens showed significantly lower values in comparison to the rural population.

In Austria, there are hardly, nationally measured and therefore objective, exact and representative data for prevalence of overweight and obesity.

A representative investigation and interpretation of regional, and age related trends in young men is relevant for healthpolitical reasons as well as for the suitability for certain duties within the Austrian Federal Army. Overweight in adolescents and young adults means that mostly they will keep up their excessive body size into the middle age. Particularly men were later on exposed to raised risks for morbidity and mortality

[6, 11-14].

The identification of risk groups, caused by prosperity, malnutrition and physical

Inactivity $[15,16]$ is accurately possible by representation of connections between body composition and physical efficiency and fitness[17,18,19].

The aim of this study was to investigate temporal and regional trends of body mass

(BM), body mass index (BMI) and waist circumference (WC) of Austrian conscripts candidates from 2007 to 2016.

\section{Methods}

The data of Austrian candidates for conscription between 2007 and 2016 were provided by the Department Pers Marketing of Ministry of Defence. In six medical centres of the Austrian Federal Army [20],they were collected from all male mostly 17 or 18years (several exceptions for later call up) with Austrian citizenship and permanent residence. Every record is to be assigned to a single person about the zip code, the date of birth and the investigation date. For the measurement of data, devices were calibrated regularly.

The records were cleaned around missing data, for example, by untimely termination of investigation for medical or psychological reasons, as well as not plausible values by admission mistake (missing date of birth, missing zip code, unrealistic values of body weight or body height). Because young men increase in the possible period of call up (from $17 \mathrm{y}$ to $24 \mathrm{y}$ ) developmentally and naturally in body mass, cohorts of age were formed for the detailed analysis.For investigation of regional differences, the federal territory was divided into three regions, EAST(Vienna, Lower Austria, and Burgenland), CENTRAL(Styria, Upper Austria, Carinthia), and WEST(Salzburg, Tyrol, Vorarlberg). Besides that, young Austrians from conurbations with more than 100,000 inhabitants[22] (Vienna, Graz, Linz, Klagenfurt, Salzburg and Innsbruck) were compared to those from provincial towns and rural areas.

The statistical evaluation of data occurred with the programme IBM SPSS Statistics 18.Descriptive statistics were summarized as means, standard deviation $( \pm$ S.D) for anthropometric parameters. Comparisons of means of BM, BMI and WC among age and regions were done using one way ANOVA with Bonferroni adjustments for multiplicity of testing,effects were checked by Cohen's $d$ and $f$ eta, effect size was categorized as 0.02 small, 0.13 medium and 0.26 large.

Pearson's correlation coefficients were determined for linear associations of BMI and waist circumference. Significance was selected at $\mathrm{P}$ values $<0.05$.

\section{Results}

From 591975male conscripts age 18.3 years (y) $\pm 2.5 \mathrm{y}, 89 \%$ belonged to cohort1 
( $\leq 19 y$ ) $6.1 \%$ to cohort $2(20-21 y), 1.9 \%$ to cohort 3, (22 - 23y) and 3\% to cohort 4 $(\geq 24 y) . \quad 31.3 \%$ conscripts lived in conurbations with more than 100,000 inhabitants and $68.7 \%$ in provincial towns or in rural surroundings. Regional categorization showed that $39.1 \%$ had the main residence in the eastern region, 39.3\% in the central region as well as $21.6 \%$ in the western region.

\subsection{Body Mass, Body Mass Index and Waist Circumference}

Mean BM increased significantly from 74.1 to $75.1 \mathrm{~kg}$ by about $1 \mathrm{~kg}(\mathrm{~F}(9,591967$, $\mathrm{p}=0.000)$. The mean BMI registered a significant increase of 23.4 in 2007 on 23.6 in 2012. The values from 2012 on showed significant variations at high level

$(\mathrm{F}(9,591967, \mathrm{p}=0.000)$. Mean waist circumference registered the highest value in 2007 with $86.3 \mathrm{~cm}$ and showed in the investigation period a relatively big variation width of approx. $3 \mathrm{~cm}$. Effect sizes of the significant differences of $\mathrm{BM}$, BMI and WC were trivial ( $\mathrm{f} \leq 0.01$ ).

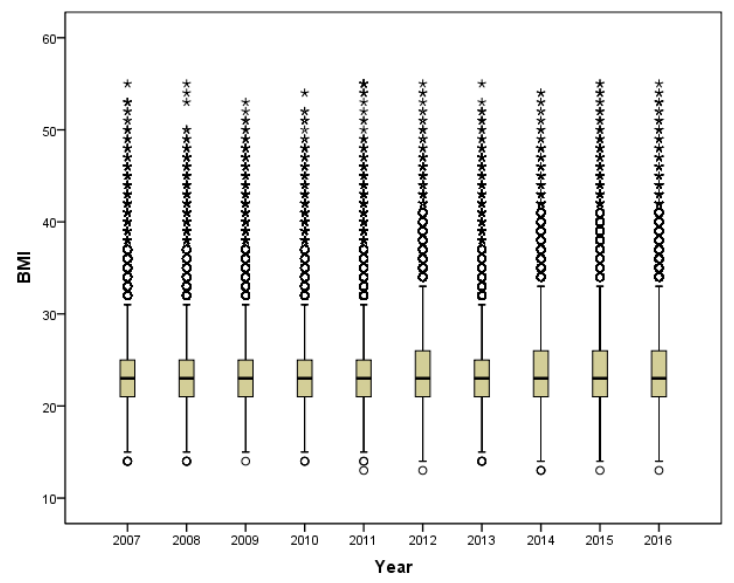

Figure 1: Distribution of body mass index between 2007 and 2016

The results showed a significant increase of the mean body mass in all cohorts of age, cohort 4 had the highest values. Also mean BMI differed significantly, in cohort 1between 23.3 and 23.6 with trend increase, in cohort 2 from 23.4 to 23.9, in cohort 3 of from 23.6 to 24.2 and in cohort 4 between 23.7 and 24.5 big arhythmical annual variations were ascertained.

The range for prevalence of overweight (BMI 25-29,9) in the period was between 20 and $21.9 \%$ (mean $20.8 \%$ ), for obesity I (BMI $30-34,9$ ) between 5.9 and 6.6\% (mean $6.3 \%$ ) and for obesity II $(\mathrm{BMI} \geq 35)$ between 2.3 and $2.6 \%$ (mean $2.5 \%$ ).

\subsection{Regional Trends}

Regional differences (see Tab 1) were detected, mean $\mathrm{BM}$ raised by $0.9 \mathrm{~kg}$, mean BMI $0.4 \mathrm{~kg} / \mathrm{m}^{2}$ and $\mathrm{WC}$ about $2.7 \mathrm{~cm}$ from western to the eastern region. Like the values of the overall collective of candidates, the data of the regions showed a clear growth of mean BM and BMI till 2010 and stabilisation later on.

Table 1: Significant differences of body mass, body mass index and waist circumference

\begin{tabular}{|l|l|l|l|l|l|l|}
\hline & \multicolumn{2}{|c|}{ BM_kg } & \multicolumn{2}{c|}{ BMI_kg/m } & \multicolumn{2}{c|}{ WC_cm } \\
\hline East & 74.8 & & 23.7 & & 85.9 & \\
Cent & 74.8 & .394 & 23.5 & $.000 *$ & 85.4 & $.000^{*}$ \\
West & 73.9 & $.000 *$ & 23.3 & $.000^{*}$ & 83.2 & $.000^{*}$ \\
\hline Cent & 74.8 & & 23.5 & & 85.4 & \\
East & 74.8 & .394 & 23.7 & $000 *$ & 85.9 & $.000^{*}$ \\
West & 73.9 & $.000^{*}$ & 23.3 & $.000^{*}$ & 83.2 & $.000^{*}$ \\
\hline West & 73.9 & & 23.3 & & 83.2 & \\
EastCent & 74.8 & $.000^{*}$ & 23.7 & $.000^{*}$ & 85.9 & $.000^{*}$ \\
& 74.8 & $.000^{*}$ & 23.5 & $.000^{*}$ & 85.4 & $.000^{*}$ \\
\hline
\end{tabular}

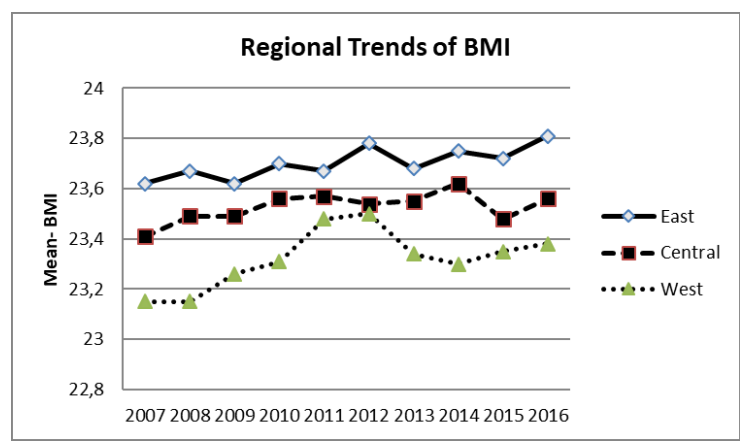

Figure 2: Trends of BMI in different regions

The comparison of mean BM, BMI and WCof conscripts with main residence in the conurbations $\geq 100,000$ inhabitants showed significant differences ( see Tab 2) 
They had lower body mass of $0.7 \mathrm{~kg}$ $(\mathrm{t}(591975)=-16.428, \mathrm{p}=0.000)$ and therefore a 0.2 lower BMI $(\mathrm{t}(591975)=$ $-20.349, p=0.000)$ and conspicuously waist circumference was $0.4 \mathrm{~cm}$ larger $(\mathrm{t}(591975)=-14.471, \mathrm{p}=0.000)$, the effect size dedectet was trivial $(\mathrm{f} \leq 0.1)$.

Table 2: Mean of body mass, body mass index and waist circumference in comparison of conurbations - rural areas

\begin{tabular}{|l|c|c|c|}
\hline Conurbation / Rural area & BM_kg & BMI_kg/m ${ }^{2}$ & WC_cm \\
\hline Conurbbations & $74.1^{*}$ & $23.4^{*}$ & $85.4^{*}$ \\
Rural areas & $74.8^{*}$ & $23.6^{*}$ & $85.0^{*}$ \\
Cohen's d effect size & 0.05 & 0.06 & 0.04 \\
\hline
\end{tabular}

\section{Discussion}

The present data are to be considered as representative for male population $[20,21,24]$ with Austrian citizenship, about $90 \%$ of the suitable cohort are grasped with call up, nearly $99 \%$ of the examined are at that time between 17 and 20 years old $[2,21]$,but evaluations about anthropometric development of young men with immigration background without Austrian citizenship are not possible.

The reliability of the records is given by the strict nationwide standardisation of the collection process of these data[20,21], even thougherror susceptibility of measurement of waist circumference is known$[9,10]$ and differs in reliability clearly from studies with self-reports data about body height, BM, BMI and WC [24,25].

As in other regional and global studies $[2,4,17,23]$ the mean BMI registered a significant increase of 23.4 in 2007 to the highest ascertained value 23.6 in 2012 . The values from 2010 on showed significant variations at high level [23].

The increase of prevalence of overweight in average on $20.8 \%$ and from obesity on $8.7 \%$ in comparison to previous other studies $[1,3,23]$ is alarming, because overweight in combination with high waist circumference is indicating an unfavourable fat distribution.
A significant high correlation was ascertained by BM BMI and $\mathrm{WC}$ in the cohorts of age from Grp1 ( $\leq 19 \mathrm{y}) \mathrm{r}=0.765$ up to Grp $4(\geq 24 y) r=0.813$ [27,28]. Even if the forecast exactness for overweight and negative health effects by BMI and waist circumference is controversially discussed $[6,29,30]$ from the significant raise of $\mathrm{BM}$, $\mathrm{BMI}$ and $\mathrm{WC}$ an increase of the risk of heart circulation illnesses, high blood pressure, diabetes Typ2, as well as a loss of the general physical fitness can be predicted $[11,12,19]$.

Overweight or obesity, caused by physical inactivity and false nutrition, in the crossing of the development from adolescence to adulthood, also hides a high risk for harmful fat distribution in the later sections of life [31-35].

The detected regional differences of raised mean BM of0.93 kg, mean BMI of $0.38 \mathrm{~kg} / \mathrm{m}^{2}$ and mean WC of $2.7 \mathrm{~cm}$ increasing from western to the eastern region showed a clear growth from 2007 to 2010 like in the overall collective. From the investigated data, an interpretation of the causes is not possible.

International investigations show also regional differences. These are explained with socioeconomic sphere terms, different educational levels and different possibilities for the access to sports infrastructure [16, $32,35,36]$.

\section{Conclusion}

To sum up, the results show another significant increase of body weight, BMI and waist circumference during the investigation period. Besides, older conscripts differ significantly from young men. The increase of prevalence of overweight and obesity progressed in the Austrian society and the percentage of the risk groups of co-morbidities as high blood pressure, chronic metabolic syndrome, diabetes type 2 or cardiovascular diseases will rise. Regional differences as well as significant differences between urban and rural population were made visible like in 
other studies $[2,3,17,28]$. The representative data and the constant evaluation standards guarantee a very good base for identification of risk groups with predicted health problems and expected overuse injuries during military basic training.
With further studies, it could be the base for exercise programmes and nutrition recommendations to the elevation of public health.

\section{References}

[1] Floris J, Koepke N, Bender N, Rühli F, Staub K: Der Body Mass Index der SchweizerStellungspflichtigen 2015 (Teil A).Fünfter Wissenschaftsaustausch MOSEB.

[2] Lean M E J, Katsarou C, McLoone P,Morrison D S:Changes in BMI and waist circumference in Scottish adults: use of repeated cross-sectional surveys to explore multiple age groups and birth-cohorts. International Journal of Obesity,37(Suppl 6): 800803, 2013.

[3] Wallner A, Hirz A, Schober E, Harbich H, Waldhoer T:Evolution of cardiovascular riskfactors among 18-year-old males in Austria between 1986 and 2005. Wiener klinischeWochenschrift,122(5): 152-158, 2013.

[4] Ng M, Fleming T, Robinson M, Thomson B, Graetz N, Margono C, Abraham J P:Global, regional, and national prevalence of overweight and obesity in children and adults during1980-2013: a systematic analysis for the Global Burden of Disease Study 2013. The lancet,384(9945): 766-781, 2014.

[5] Malara M, Kęska A, Tkaczyk J, Lutosławska G:Body shape index versus body mass index as correlates of health risk in young healthy sedentary men. Journal of translational medicine,13(1): 75, 2015.

[6] Ortega F B, Sui X, Lavie C J, Blair S N:Body mass index, the mostwidely used but also widely criticized index: would a criterion standard measure of total body fat be a better predictor of cardiovascular disease mortality?.Mayo Clinic Proceedings, 9(4): 443-455, 2016.

[7] Roh L, Braun J, Chiolero A, Bopp M, Rohrmann S, Faeh D:Mortalityrisk associated with underweight: a census-linked cohort of 31,578 individuals with up to 32 years of followup. BMC Public Health,14(1): 371, 2014.

[8] Becker S, Zipfel S, Teufel M: Diagnosekriterien der Adipositas. In Psychotherapie der Adipositas: Interdisziplinäre Diagnostik und differenzielle Therapie. Kohlhammer Verlag; 10-12, 2015.

[9] Ravensbergen H R, Lear S A, Claydon V E: Waist circumference is the best indexfor obesity-related cardiovascular disease risk in individuals with spinal cord injury. Journal of neurotrauma, 31(3): 292-300, 2014.

[10] Javed A, Jumean M, Murad M H, Okorodudu D, Kumar S, Somers V K, Lopez Jimenez F: Diagnostic performance of body mass index to identify obesity asdefined bybody adiposity in children and adolescents: a systematic review and meta-analysis. Pediatric obesity, 10(3): 234-244, 2015.

[11] Aune D, Sen A, Norat T, Janszky I, Romundstad P, Tonstad S, Vatten L J:Body mass index, abdominal fatness and heart failure incidence and mortality: a systematic review and dose-response meta-analysis of prospective studies. Circulation, CIRCULATIONAHA-115, 2016.

[12] Malara M, Kęska A, Tkaczyk J, Lutosławska G: Body shape index versusbody mass index as correlates of health risk in young healthy sedentary men. Journal of translational medicine, 13(1): 75, 2015. 
[13] Fernström M, Fernberg U, Eliason G, Hurtig-Wennlöf A: Aerobic fitnessis associated with low cardiovascular disease risk: the impact of lifestyle on early risk factors for atherosclerosis in young healthy Swedish individuals-the Lifestyle, Biomarker, and Atherosclerosis study. Vascular health and risk management, 13: 91, 2017.

[14] McAuley P A, Beavers K M:Contribution of cardiorespiratory fitness to the obesity paradox. Progress in cardiovascular diseases, 56(4): 434-440, 2014.

[15] Freedman D S, Ogden C L, Kit B K: Interrelationships between BMI, skin fold thicknesses, percent body fat, and cardiovascular disease risk factors among US children and adolescents.BMC paediatrics, 15(1): 188, 2015.

[16] Rönnlund M, Sundström A, Pudas S:Midlife level and 15-year changes in general cognitive ability in a sample of men: The role of education, early adult ability, BMI, and pulse pressure. Intelligence, 61: 78-84, 2017.

[17] Lehmann, Andreas, et al: Temporal trends, regional variation and socio-economic differences in height, BMI and body proportions among German conscripts, 19562010.Public Health Nutrition, 20(3): 391-403, 2017.

[18] Vaara, Jani P., et al. Associations of maximal strength and muscular endurance test scores with cardio respiratory fitness and body composition."The Journal of Strength \& Conditioning Research, 26 (8): 2078-2086, 2012.

[19] Taanila Henri et al: Low physical fitness is a strong predictor of health problems among young men: a follow-up study of 1411 male conscripts.BMC Public Health, 11(1) : 590, 2011.

[20] Bundesministerium für Landesverteidigung und Sport: Handbuch ErgänzungswesenStellung. Kapitel 3, Rechtsförmliche Verfahren betreffend Feststellung der Eignung zum Wehrdienst durch die Stellungskommissionen gemäß Wehrgesetz 2001-WG 2001,BGBl. Nr.14; 2014.

[21] Bundesministerium für Landesverteidigung und Sport: Handbuch ErgänzungswesenStellung. Kapitel 4, Verfahren in der Stellungsstraße betreffend Feststellung der Eignung zum Wehrdienst durch die Stellungskommissionen gemäß Wehrgesetz 2001WG 2001, BGBl. Nr.14; 2014.

[22] Version von Stadt [https://wirtschaftslexikon.gabler.de/definition/stadt-43260/version266591] Accessed on 19.02.2018 - 16:05

[23] Panczak R, Woitek U, Rühli F, Staub K: Regionale und sozio-ökonomische Unterschiedeim Body Mass Index (BMI) von Schweizer Stellungspflichtigen 2004-2012. Zürich: Projektschlussbericht zuhanden des Bundesamtes für Gesundheit (BAG); 2013.

[24] Schienkiewitz A, Mensink G, Kuhnert R, Lange C: Übergewicht und Adipositas beiErwachsenen in Deutschland. Journal ofHealth Monitoring, 2(2): 3-7, 2017.

[25] Hauner H, Bramlage P, Lösch C, Steinhagen-Thiessen E, Schunkert H, Wasem J, Moebus S: Prävalenz und regionale Verteilung von Übergewicht und Adipositas nach Body-Mass-Index und Bauchumfang in der hausärztlichen Versorgung in Deutschland.Aktuelle Ernährungsmedizin, 32(05): 19,2007.

[26] Pietiläinen K H, Kaprio J, Borg P, Plasqui G, Yki-Järvinen H, Kujala U M, Rissanen A: Physicalinactivityandobesity: a viciouscircle.Obesity, 16(2): 409-414, 2008.

[27] Vlassopoulos A, Combet E, Lean, M. E: Changing distributions of body sizeand adiposity with age. International journal of obesity, 38(6): 857, 2014.

[28] Ng M, Fleming T, Robinson M, Thomson B, Graetz N, Margono C, Abraham J P:Global, regional, and national prevalence of overweight and obesity in children and adults during 1980-2013: a systematic analysis for the Global Burden of Disease Study2013.The lancet, 384(9945): 766-781, 2014. 
[29] Janssen I, Katzmarzyk P T, Ross R: Waist circumference and not body massindex explains obesity-related health risk. The American journal of clinical nutrition, 79(3): 379-384, 2004.

[30] Nye N S, Kafer D S, Olsen C, Carnahan D H, Crawford P F:Abdominal Circumference Versus Body Mass Index as Predictors of Lower Extremity Overuse Injury Risk. Journal of Physical Activity and Health, 20(XX): 1-8, 2017.

[31] McCambridge TM, Bernhardt DT, Brenner JS, Congeni JA, Gomez JE, Gregory AJM, Gregory DB, Griesemer BA, Reed F E, Rice S G, Small E W: Active healthy living: preventionof childhood obesity through increased physical activity. Pediatrics, 117:1834-1842, 2006.

[32] Jung Y J, Shin J H, Yum, K S, Song C H, Choi W S, Kim K S, Park J H: The association between obesity indices and physical fitness.Journal of the Korean Academy of Family Medicine, 24(3): 271-278, 2003.

[33] Crump, Casey, et al: Interactive effects of physical fitness and body mass index on the risk of hypertension. JAMA internal medicine, 176(2) : 210-216, 2016.

[34] Havenetidis, Konstantinos, et al: Prognostic potential of body composition indices in detecting risk of musculoskeletal injury in army officer cadet profiles.The Physician and Sportsmedicine just-accepted (2017).

[35] Ortega F B, Ruiz J R, Castillo M J, Sjöström M:Physical fitness in childhood andadolescence: a powerful marker of health. International journal of obesity, 32(1): 1, 2008.

[36] Panczak R, Zwahlen M, Woitek U, Rühli F J, Staub K: Socioeconomic, temporal and regional variation in body mass index among 188,537 Swiss male conscripts born between1986 and 1992. PLoS One, 9(5), e96721, 2014. 